\title{
Access to treatment for HIV/AIDS: Report of a meeting of international experts
}

Johannes van Dam

Sherry Hutchinson

Population Council

Follow this and additional works at: https://knowledgecommons.popcouncil.org/departments_sbsr-hiv

Part of the International Public Health Commons, and the Public Health Education and Promotion Commons

How does access to this work benefit you? Let us know!

\section{Recommended Citation}

van Dam, Johannes and Sherry Hutchinson. 2002. "Access to treatment for HIV/AIDS: Report of a meeting of international experts," Horizons Report. Washington, DC: Population Council. 


\section{Hgrizons}

\section{Access to Treatment for HIV/AIDS}

Report of a Meeting of International Experts 12-13 June 2001 Washington, DC, USA

Horizons Program

Published in 2002 


\section{Access to Treatment for HIV/AIDS}

Report of a Meeting of International Experts

$12-13$ June 2001
Washington, DC, USA

Johannes van Dam, M.D., M.Sc.

Sherry A. Hutchinson 


\section{Acknowledgments}

The authors would like to thank all of the participants who made presentations at the meeting and acknowledge the contributions of Eric van Praag, Andy Fisher, Avina Sarna, Naomi Rutenberg, and David Stanton to this publication. In addition, we would like to thank Sharon Schultz for editorial support and recognize Ellen Weiss and Margaret Dadian for their constructive criticisms and suggestions for this report.

USAID This study was supported by the Horizons Program, which is implemented by the Population Council in collaboration with the International Center for Research on Women, International HIV/AIDS Alliance, Program for Appropriate Technology in Health, the University of Alabama Vill at Birmingham, Tulane University, Family Health International, and Johns Hopkins University. Horizons is funded by the U.S. Agency for International Development, under the terms of HRNA-00-97-00012-00. The opinions expressed herein are those of the authors and do not necessarily reflect the views of the U.S. Agency for International Development.

Published in March 2002.

\section{TP Population Council}

The Population Council is an international, nonprofit, nongovernmental institution that seeks to improve the wellbeing and reproductive health of current and future generations around the world and to help achieve a humane, equitable, and sustainable balance between people and resources. The Council conducts biomedical, social science, and public health research and helps build research capacities in developing countries. Established in 1952, the Council is governed by an international board of trustees. Its New York headquarters supports a global network of regional and country offices.

Copyright (C) 2002 The Population Council Inc. 


\section{Table of Contents}

Introduction $\quad 1$

Statement of the problem 1

Antiretroviral therapy programs: Issues and considerations 3

Critical Aspects of Treatment Programs 9

Health systems and service delivery 9

$\begin{array}{ll}\text { Biomedical issues } & 14\end{array}$

$\begin{array}{ll}\text { Behavioral issues } & 14\end{array}$

$\begin{array}{ll}\text { Stigma, discrimination, and ethical issues } & 17\end{array}$

$\begin{array}{ll}\text { Community involvement } & 19\end{array}$

Cost and cost recovery $\quad 20$

$\begin{array}{ll}\text { Policy } & 21\end{array}$

$\begin{array}{ll}\text { Programmatic implications } & 22\end{array}$

$\begin{array}{ll}\text { Conclusion } & 23\end{array}$

$\begin{array}{ll}\text { High-priority operations research questions } & 23\end{array}$

$\begin{array}{ll}\text { References } & 26\end{array}$

Appendixes

$\begin{array}{ll}\text { A. Recommended further reading } & 27\end{array}$

B. List of participants at Horizons Access to Treatment meeting 28

$\begin{array}{ll}\text { C. Meeting objectives and agenda } & 34\end{array}$ 



\section{Introduction}

\section{Statement of the Problem}

As of December 2001, the total number of people living with HIV/AIDS (PLHA) is estimated at 40 million. Most of these people live in the developing world (UNAIDS and WHO 2001). While there are indications that the incidence of HIV infection has been declining in some countries, in many others incidence rates remain high or are increasing. Consequently, the prevalence of HIV infection is likely to continue to rise. In the absence of treatment, most people infected with HIV will eventually develop an HIV-related disease and succumb to the consequences of the infection.

Advances in the development and availability of antiretroviral drugs have led to a paradigm shift in most of the industrialized world, where highly active antiretroviral therapy (HAART) has resulted in a significant reduction in the prevalence of AIDS-related morbidity and mortality. AIDS has, in the eyes of many, become a manageable chronic disease.

In most of the developing world, however, the focus of national programs and international support continues to be on prevention, care, and support in the absence of antiretroviral treatment. Notable exceptions are Brazil, Thailand, Senegal, and Botswana, which have made antiretrovirals (ARVs) available to people with AIDS through public sector efforts. Other exceptions include countries that have initiated pilot antiretroviral treatment programs, including Côte d'Ivoire, Uganda, Chile, and Vietnam.

While the moral imperative to provide the best possible treatment for people with AIDS-related disease is widely recognized, national governments and donors have been reluctant to enter into this endeavor. They cite numerous concerns, ranging from the cost of ARVs to the capacity of health care delivery systems in the developing world to the ability of patients to adhere to lifelong treatment regimens. However, the cost of antiretroviral drugs continues to decrease and ARVs are now available through private channels in almost all countries in the world. The above-mentioned concerns remain, however, and both ministries of health and the international donor community need guidance on how to develop and implement appropriate and effective HIV/AIDS treatment programs.

A successful treatment program is the result of the synergy between a large number of components. In an ideal situation, appropriate drugs with few or no side effects are accessible and affordable to those who need them. Those who need the drugs seek and adhere to treatment freely and without fear of stigmatization or discrimination, and health care workers monitor treatment and adapt regimens to suit individual patients. While impressive progress has been made in many of these areas of HIV/AIDS treatment, numerous challenges and questions remain.

To explore and prioritize operations research questions about access to treatment for HIV/AIDS, the Horizons Program convened a two-day meeting of international researchers and program 


\section{Hgrizons}

managers in Washington, D.C., on 12-13 June 2001. The meeting focused specifically on the following key questions:

- What are the operational issues encountered in providing HIV/AIDS treatment in different settings?

- What are the most important operational challenges and testable solutions in providing access to treatment?

- How do these challenges and solutions differ by region and subpopulation?

- What are some of the important research design and measurement issues that need to be considered in addressing key issues concerning access to treatment?

This report presents the findings and recommendations discussed at the meeting. The report begins with a summary review of aspects of antiretroviral programs and then discusses the following critical elements of treatment programs:

- Health systems and service delivery

- Biomedical issues

- Behavior of health care workers and clients

- Stigma, discrimination, and ethical issues

- Community involvement

- Cost and cost recovery

- Policy

- Programmatic issues

The discussions at the two-day meeting covered a wide range of topics at times, but an effort has been made in this report to concentrate on the important operational issues concerning access to treatment that need to be addressed through research. It is recognized that treatment for HIV/AIDS is more than antiretroviral therapy; rather, it includes treatment of opportunistic infections and palliative and end-of-life care. While the discussion focused on treatment with ARVs, many of the issues raised and the research questions identified also pertain to treatment of opportunistic infections and the provision of palliative and end-of-life care.

Finally, the participants at the meeting brought to the table a rich and diverse experience with HIV/AIDS treatment, care, support, and prevention. Most participants made short presentations that provided the basis for in-depth discussion. For the purposes of this report it did not seem desirable to summarize every presentation, but rather to ensure that the substance of the presentations is accurately reflected. 


\section{Antiretroviral Therapy Programs: Issues and Considerations}

The availability of HAART in the industrialized world has greatly reduced AIDS-related mortality, while the number of PLHA in many countries continues to increase. Thus, in the United States, the number of PLHA increased from 174,244 in 1993 to 317,368 in 1999, while mortality associated with AIDS decreased from 45,494 to 16,767 in that same period (CDC 2000). Initially the cost of ARVs was perceived as an insurmountable obstacle to wide-scale provision of antiretroviral therapy in the developing world. However, recently these costs have come down to levels that are affordable to at least some national health systems outside of the industrialized world and to some individuals in even the poorest countries. For instance, the cost of triple antiretroviral therapy has decreased from US\$800-1,100 per month to US\$100-300 per month. This still represents an enormous cost, however, especially in relatively poor countries with a high prevalence of HIV infection. Nonetheless, the cost of not providing antiretroviral therapy is also enormous in terms of morbidity and mortality, declining agricultural and industrial productivity, increased numbers of orphans, and great economic hardships for affected families.

\section{Comprehensive prevention, care, and support}

It is important to realize that antiretroviral therapy is only one component of a comprehensive HIV/AIDS program that also includes prevention and other care and support activities. Figure 1 provides a schematic overview of a comprehensive HIV/AIDS care program. These components not only complement but also mutually reinforce each other. Treatment programs are developed and implemented in the context of existing health care delivery systems. Other components of HIV/AIDS treatment and care include counseling and testing; the control and management of sexually transmitted infections (STIs); prophylaxis for certain opportunistic infections (OIs), such as tuberculosis (TB) and pneumocystis carinii pneumonia (PCP); treatment for OIs; and palliative care. Many PLHA will not initially qualify for antiretroviral therapy, and not all who receive antiretroviral therapy benefit equally. Studies in the industrialized world demonstrate highly variable rates of long-term suppression of viral particles in the peripheral blood, ranging from 32 percent in patients who received antiretrovirals before initiating HAART to 37-82 percent in patients who had never received antiretroviral treatment (Lucas et al. 1999; Servais et al. 2000; Yamashita et al. 2001). Lack of long-term benefit is strongly associated with less-than-perfect adherence, treatment discontinuation, and viral resistance, and possibly with the number of CD4 cells present at treatment initiation. A significant number of people on HAART discontinue treatment because of serious side effects or psychological and emotional strain. 
Fiqure 1 Overview of comprehensive HIVIAIDS care proqram

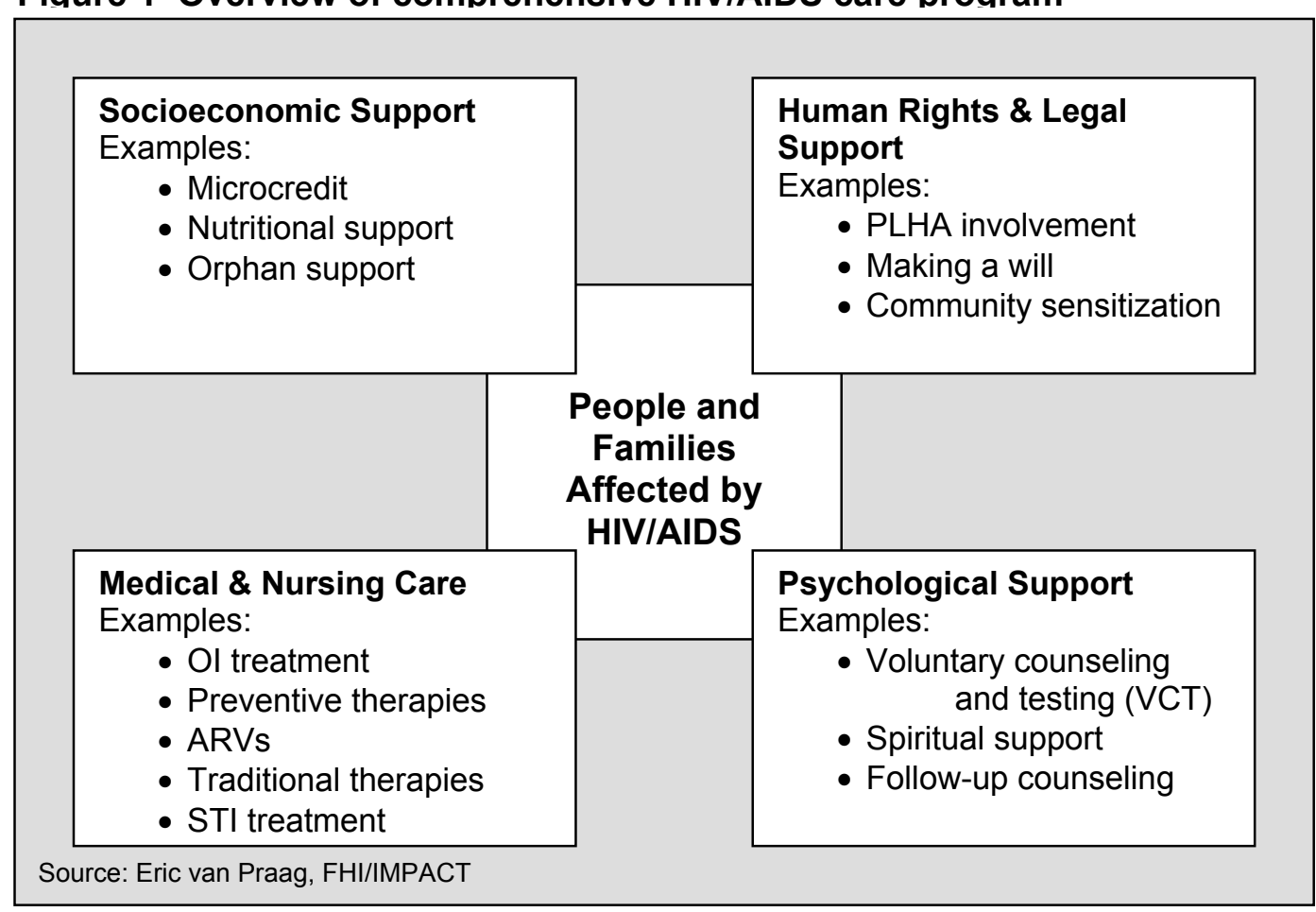

Although antiretroviral treatment is a rapidly evolving field and experience with such programs is relatively limited, it is nevertheless clear that as a component of comprehensive care and support programs ARVs can reduce HIV-related morbidity and mortality and improve the quality of life of people living with HIV/AIDS. Antiretroviral treatment might also contribute to reduced transmission of HIV by lowering the viral load and thus reducing the infectiousness of PLHA. The availability of antiretroviral therapy is likely to provide an incentive to seek voluntary counseling and testing (VCT) and to learn about one's serostatus, which in turn might contribute to safer sexual behavior.

Despite the many problems of antiretroviral treatment programs, they have the potential to significantly complement and enhance comprehensive HIV care and support programs, and, possibly, other health care programs. (Eric van Praag, FHI/IMPACT)

\section{Antiretroviral drugs, resistance, and treatment monitoring}

Currently, there are three classes of drugs that block replication of HIV in the cell:

- Nucleoside reverse transcriptase inhibitors (NRTI)-such as zidovudine (AZT), 3TC, ddI, $\mathrm{d} 4 \mathrm{~T}, \mathrm{ddC}$, and Combivir (a combined preparation with AZT and 3TC) 
- Non-nucleoside reverse transcriptase inhibitors (NNRTI)-such as nevirapine, delavirdine, and efavirenz

- Protease inhibitors (PI)-such as ritonavir, indinavir, nelfinavir, and saquinavir

Each class of drugs has its own side effects, many of which are potentially very serious. Common side effects are headache, nausea, vomiting, fatigue, and diarrhea. Some people have problems eating or sleeping. Some other complications associated with specific classes of drugs include lipodystrophy (fat redistribution) syndrome, hepatomegaly (liver enlargement), pancreatitis, and anemia. It is important that both health care workers and people taking antiretroviral therapy are well aware of these side effects.

A combination of drugs from different classes is required for a sustained reduction of the viral load in the peripheral blood, because resistance to a single drug usually develops rapidly. At the very least, treatment regimens should provide for double therapy, but optimal regimens consist of a combination of three drugs. Current recommendations for triple therapy are two NRTIs and one PI or two NRTIs and one NNRTI. The only exception to these recommendations is related to the prevention of mother to child transmission (MTCT), for which treatment of mother and child with a single drug has been shown to reduce significantly the incidence of HIV infection in the newborn baby. Treatment regimens are becoming easier to follow by combining different drugs in one pill or capsule and by developing formulations that require less frequent dosages. Still, some drugs require refrigeration for storage, and there is no single ideal combination of drugs. For optimal patient management, careful monitoring of the clinical response to a treatment regimen is needed so that treatment can be adapted to suit the clinical and immunological response as well as the needs of the individual patient.

The development of HIV drug-resistant strains is a concern, especially when treatment is interrupted because of irregular adherence to treatment. Irregular adherence may be due to interruptions in the supply of drugs, problems with access to services, serious side effects, intermittent ability to pay for the drugs, or a patient's increased sense of wellbeing. The fact that currently available antiretroviral therapy needs to be taken lifelong might also contribute to adherence problems. Resistant strains not only are a problem in the management of individual patients, but also could theoretically limit the usefulness of one or more classes of antiretroviral drugs at the community level.

An additional complication is that many ARVs interact with other drugs that are commonly prescribed in developing countries, increasing the toxicity of some drugs and reducing the efficacy of others. This is the case, for instance, with rifampicin, commonly used for the treatment of tuberculosis, which reduces the efficacy of amprenavir, saquinavir, indinavir, and nelfinavir. It is important that physicians prescribing and monitoring antiretroviral therapy have a good understanding of these issues.

Drug therapy for HIV/AIDS is rapidly evolving, and it is likely that treatment recommendations will continue to change as new drugs and new formulations become available. Treatment programs should be aware of this and remain flexible so they can be adapted to new developments. 


\section{Hgrizons}

The impact of HAART is usually measured through assessments of the CD4 count and of the viral load in the peripheral blood. The CD4 count (the number of T-lymphocytes with a CD4 receptor) is a measure of the degree to which HIV compromises the immune system, while the viral load measures the number of circulating viral particles. The CD4 count is also used as a criterion for the initiation of treatment; persons whose CD4 count falls below a certain threshold are considered eligible for treatment with ARVs. These tests are expensive, however, costing roughly $\$ 100$ per viral load test and $\$ 30$ per CD4 test, and they demand highly qualified and well-trained laboratory staff, well-equipped laboratories, and high levels of quality control.

\section{Antiretroviral drugs and the health care system}

Implementing an antiretroviral therapy program places an additional strain on a health care system, in terms of its logistics, the providers, and the laboratory support system. Providers in the public sector as well as in the private sector, where antiretroviral drugs are generally more widely available, need to be trained and prepared to provide continuing clinical follow-up. Access to highquality care may be further compromised because of generally high levels of attrition among physicians and nursing staff resulting from HIV infection (of themselves or their families), low wages, burnout, and lack of motivation. A consistent supply of antiretroviral drugs must be available in order to avoid arbitrary treatment interruptions, and there should be sufficient laboratory capacity to do the initial testing, to assess a person's HIV status, and to monitor CD4 counts and viral loads. An intensive clinical and laboratory monitoring and information system also needs to be implemented.

Although drug costs have dropped recently, the cost of antiretroviral drugs still remains considerable for most individuals and treatment programs. Added to the cost of drugs are the cost and effort required to strengthen and maintain the capacity of health care systems to deliver appropriate treatment programs. An HIV/AIDS treatment program could lead to new partnerships in health care delivery, for example, between the public and private sector, and to the strengthening of the overall health care system. However, it could also result in situations in which antiretroviral therapy programs are in competition for resources with other health care programs, and in which an emphasis on HIV/AIDS treatment leads to a deterioration of other programs, including HIV prevention efforts.

\section{Behavior, stigma, and discrimination}

Persons taking antiretroviral therapy may see less need to adopt or maintain safe behaviors because they mistakenly believe the treatment is curing them or that the virus is sufficiently suppressed to render them noninfectious. Similarly, the perception of ARVs as a cure for AIDS may also undermine behavior change programs and result in fewer people adopting or maintaining safe behaviors. A recent increase in high-risk behaviors among men who have sex with men in the United States has been associated with the availability of HAART (Remien 1998; Scheer 2001). 
There are indications that with the widespread availability of HAART and the perception of AIDS as a manageable, chronic condition, levels of stigma and discrimination in the industrialized world may have decreased. However, in many parts of the industrialized world and in most of the developing world, PLHA are still subject to considerable stigmatization and discrimination. While increased availability of ARVs in the developing world might reduce stigma and discrimination, communities and PLHA also need to be involved in HIV/AIDS treatment programs to achieve this goal. It is likely that increased availability of ARVs will result in increased demands for voluntary counseling and testing and that antiretroviral therapy will result in increased disclosure, either voluntary or involuntary. Community and PLHA involvement could contribute significantly to reducing stigmatization while providing a supportive environment for all PLHA. Such a supportive environment could also play an important role in adherence to treatment recommendations. However, the current levels of actual or perceived stigma may still prevent people from seeking VCT and from accessing ARV programs, especially those provided by employers.

\section{Access and equity}

Not all people living with HIV need antiretroviral therapy. Whether a decision to treat is based on the CD4 count, viral loads, evidence of HIV-related disease, or a combination of these factors, it is likely that initially only a relatively small proportion of all those who are HIV-positive would qualify for antiretroviral therapy. Moreover, a patient's readiness to start treatment needs to be taken into account. This requires a thorough understanding of the need to adhere to a relatively complex treatment that is to be taken lifelong. The number of patients eligible to start a treatment regimen is still substantial, with estimates on the order of 10-15 percent of those who are HIVpositive or 3-5 million people worldwide. Over time, as more HIV-positive individuals progress to HIV-related disease and fewer people die of AIDS, this number could rise considerably. In many cases the cost of treatment and differences in the capacity of health care systems within countries will result in unequal access to treatment. Issues of equity will need to be addressed, although it is not possible to wait until a perfect system is in place before beginning treatment programs. The effect of insufficient VCT services, inadequate health care-seeking behavior, and the lack of easily accessible and affordable treatment is shown in Figure 2. 
Figure 2 Estimated proportion of HIV-infected people benefiting from effective use of ARV drugs: A theoretical model

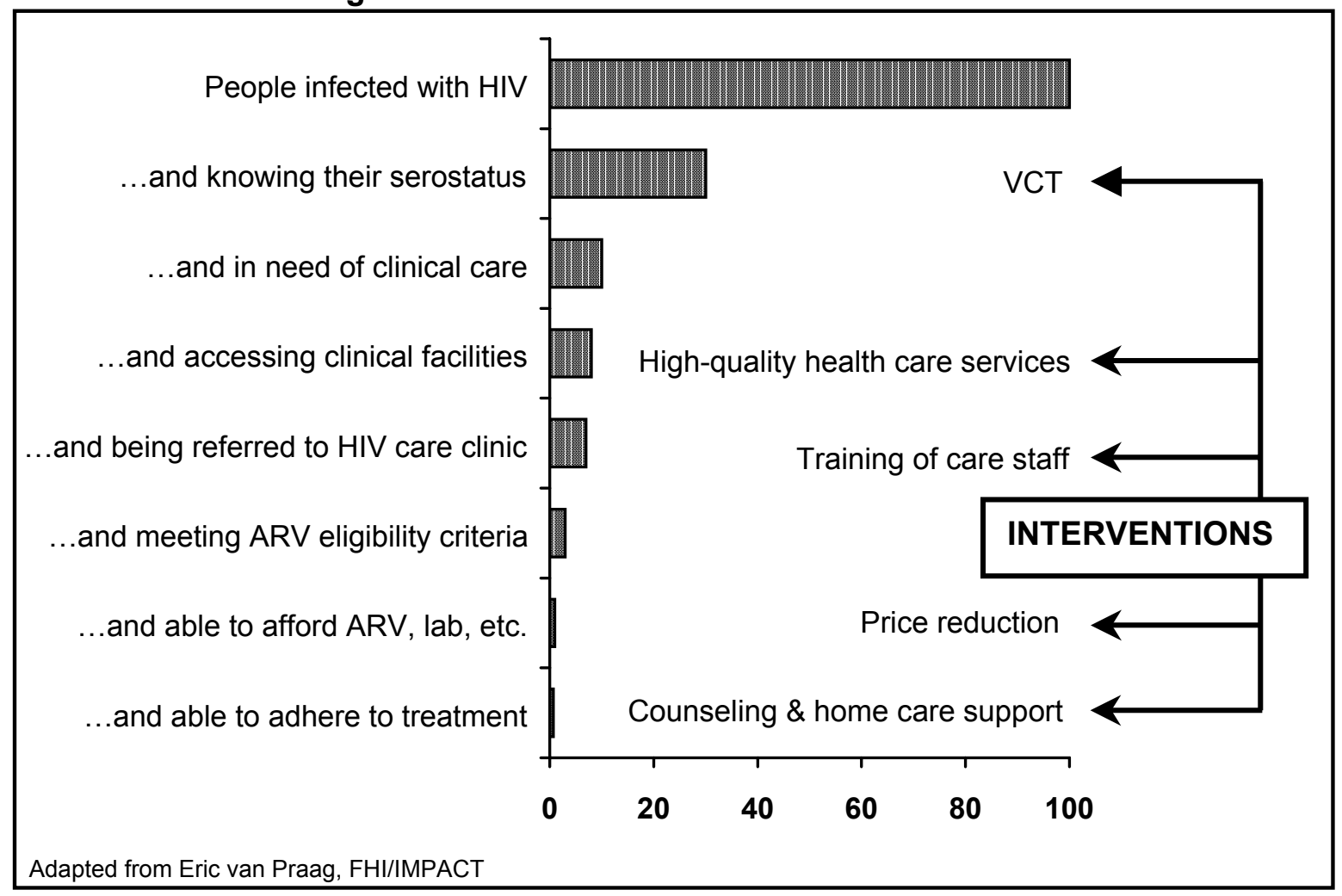

Equity in access to treatment is especially important if the overriding goal of an HIV/AIDS treatment program is to achieve a therapeutic effect for all infected persons. Nonetheless, an argument can be made for the public health benefits of antiretroviral therapy directed at selected groups of people such as health care providers, teachers, uniformed services, truck drivers, and sex workers. Another group that could be considered are women who are found to be HIV-positive in MTCT programs and who play a crucial role as caretakers in the family. Such benefits include not only a reduction in morbidity and mortality associated with HIV/AIDS at the individual level, but also a potential reduction in transmission of HIV infection by HIV-positive individuals on antiretroviral therapy, as reductions in viral load are associated with reduced risk of transmission (Gray 2001). In the case of mothers, the benefits would include improved survival and development opportunities for her children and a reduction in the number of orphans. Pursuing the public health prevention benefits associated with antiretroviral therapy suggests that programs might focus initially on high-risk individuals or those with multiple partners and that these programs might start treatment early. Whether the focus of a treatment program is on all infected individuals or selected high-risk groups, an important question for program managers and policymakers is one of coverage. Critical decisions have to be made about which segments and what proportion of the population are to be covered by the treatment program. 


\section{Critical Aspects of Treatment Programs}

\section{Health Systems and Service Delivery}

\section{Human and institutional capacity}

Health care systems and their resource base differ from country to country and even within countries. The not-for-profit and private sectors play an important role in providing curative care for many people in the world. In fact, in most countries ARVs were available through the private sector before public sector programs were developed. Thus, a first step in the development of an HIV/AIDS treatment program is a situation analysis of the available services, capabilities, and capacity of the existing system. Particular attention should be paid to the training needs of health care personnel in the public and private sector, to the quality and location of laboratory services, and to the existing infrastructure for drug procurement and distribution. As was pointed out earlier, the care and treatment needs of PLHA are not met by ARVs alone. Services for VCT need to be available; tuberculosis and other OIs need to be diagnosed and treated; prophylaxis for some OIs can be provided; and palliative and end-of-life care is required for many infected persons. The majority of people who are HIV-positive will in fact be asymptomatic; therefore, once they know their HIV status, they will initially need psychosocial support the most.

A crucial element of a health care system is its staff. The initial situation analysis should pay attention not only to their levels of knowledge, but also to their motivation and commitment and to their attitudes toward people living with HIV/AIDS. Frequently, health care workers in the developing world are overworked and underpaid. They lack supplies, support, and supervision; they suffer from low morale and poor motivation; and they might fear occupational exposure to HIV infection. Care for PLHA is often seen as a waste of resources, because those patients are expected to die anyway. In addition, in many places stigma and discrimination lead to a rejection of HIV-positive individuals. Therefore, approaches to improve the capacity of health care systems to provide treatment, care, and support should focus not only on building skills and increasing knowledge, but also on improving the motivation and morale of staff and on strengthening health care systems.

Health care systems in many countries suffer from a general lack of resources that leads to situations in which even essential drugs are often not available, supplies and equipment such as protective gloves are lacking, and even the presence of running water and electricity cannot be taken for granted. In turn, such health systems often function against a larger background of developmental and economic problems, characterized by corruption, internal displacement, civil strife, poor sanitation and water supply, unemployment, and internal and external migration. Or, as one participant put it: "We need better African economies."

The experience with large-scale antiretroviral therapy programs in Brazil and Thailand underscores the importance of capacity building within the health care delivery system. In Thailand, for instance, initially only a relatively small proportion of eligible persons received treatment, resulting 


\section{Hgrizons}

in only a small reduction in the national burden of HIV-related disease. Moreover, health care workers were not able to follow up on 70 percent of the patients because of a lack of infrastructure. Constraints to increasing coverage of the treatment program were identified as a lack of counseling capability, lack of health care personnel trained in ARV therapy, and a lack of clinical facilities with the capacity to monitor persons on treatment. To increase coverage of the program, qualified personnel are training staff in 60 hospitals.

\section{Making ARVs Accessible}

In Brazil, a network of facilities accredited for the provision of ARVs has been developed, where staff have been trained in both patient care and the interactions between ARVs and other drugs. Currently, 362 hospitals have been accredited to provide HIV/AIDS care. In addition to these facilities, outpatient and ambulatory care is provided through specialized care services at 148 facilities, 69 day hospitals, and 52 therapeutic home care initiatives.

Laboratory capacity to conduct CD4 testing (70 laboratories) and viral load assessments (63 laboratories) has also been developed.

The UNAIDS-supported pilot program for the provision of ARVs in four countries (Vietnam, Uganda, Cote d'Ivoire, and Chile) started with developing human resources to support the programs, while making optimal use of existing services.

In Uganda three centers for ARV treatment were operational in 1999; this is now being expanded to more than ten centers, which are expected to be qualified in 2001. In addition, planning is under way for three regional centers to provide services at the district level.

While there is no doubt that training both public and private sector health care providers in HIV/AIDS care is needed, there is also an urgent need to evaluate the effect of quality-of-care training on health service use and the impact of such training on health. Guidance and training materials have been produced by WHO, UNAIDS, and other organizations (see References for a selection of materials for further reading).

\section{Interaction between HIV/AIDS care and other programs}

Countries in the developing world are typically faced with a range of health problems. While HIV/AIDS may have become one of the leading causes of morbidity and mortality in many countries, other infectious and noninfectious diseases remain important. There is a risk that the increased focus on antiretroviral therapy programs will be at the expense of established health care programs, many of which are already in need of additional funding and strengthening. 
Within HIV/AIDS programs the allocation of resources needs to be carefully assessed. As was pointed out earlier, the provision of relatively expensive antiretroviral therapy is only one component of a comprehensive care program. It is by no means clear what the relative gains in quality-of-life and survival benefits are for those in ARV programs versus the benefits derived from less expensive prophylaxis and management programs for opportunistic infections. The UNAIDS pilot program for the provision of ARV was not able to document survival benefits or to demonstrate a reduction in the incidence of OIs and TB, possibly because many patients sought treatment very late in the course of their illness. Data from Brazil suggest that at least in the short term there is a reduction in mortality associated with the provision of HAART (Eyer-Silva 1998) and a reduction in the incidence of opportunistic infections. In Brazil, AIDS-related mortality dropped by 50 percent from $12.2 / 100,000$ population in 1995 to $6.3 / 100,000$ in 1999 , while the incidence of various OIs decreased by 60-80 percent (Ministry of Health of Brazil 2001). There is an urgent need in the developing world to evaluate both ARV treatment programs and programs for the management of OIs for their impact on morbidity and mortality.

An excessive focus on antiretroviral therapy is an impediment to establishing a comprehensive care agenda, and an obstacle to decentralization. (Jos Perriens, UNAIDS)

While some people argue that expensive ARV programs will weaken other health programs, it has been postulated that just the opposite could happen. The current attention to improving the systems for providing VCT and care for people with HIV/AIDS might also have a "ripple effect" of strengthening other health care systems. For instance, in Brazil, programs to increase access to antiretroviral therapy have increased local capacities for research, training, distribution of essential drugs, and management of complex information systems, and have led to better-integrated alliances between government, NGOs, and the community. Health planners need to balance an approach that calls for designing and implementing new systems to provide HIV/AIDS services and an approach that aims at improving and building on existing programs for providing these services. Operations research needs to determine the effect of each of these approaches.

Within HIV/AIDS programs there is a similar need to balance care and prevention. The cost and effort required to deliver high-quality care and treatment may divert resources from ongoing prevention programs. It is therefore important to assess how strengthened HIV treatment programs will affect prevention programs.

Finally, many PLHA will be need palliative and end-of-life care. This will be the case for those who do not receive antiretroviral treatment, those who stop treatment, and those in whom the virus has become resistant to the available antiretroviral drugs. Little is known about how to best provide palliative and end-of-life care and the needs of professional and lay caregivers to provide such care.

\section{Service delivery models}

A range of different service delivery models is being proposed, and operations research is needed to help evaluate the various approaches. The shortcomings of many health delivery systems in the developing world and the urgent need to address the care and support needs of ever-increasing 


\section{Hgrizons}

numbers of people who have HIV-related diseases may seem to suggest a vertical approach to HIV treatment programs. It might be easier to ensure drug logistics, prevent pilferage and misuse of antiretrovirals, and train and supervise dedicated staff in a vertical program. However, the large number of people who need care and support, the many facets of a comprehensive HIV care program, the complexities of a treatment delivery and monitoring system, and the imperative to implement programs that are sustainable suggest that an integrated approach might be more successful. An integrated approach will in many cases require a concerted effort to strengthen the health care system beyond the narrowly defined needs of an antiretroviral treatment program.

An important component of a treatment program is laboratory support. Current approaches to identifying individuals eligible for treatment with ARVs and to monitoring patients on treatment rely on CD4 and viral load tests. These tests are expensive, at US\$30 and \$100 per test, respectively, and require a sophisticated laboratory infrastructure with good quality control. An urgent need exists to evaluate alternative methods of patient follow-up that rely on fewer or less frequent laboratory tests and that might be more appropriate for many developing country settings.

\section{The tuberculosis model}

Irregular adherence to treatment will almost inevitably lead to the development of viral resistance. Antiretroviral treatment is thus very much like treatment for tuberculosis. It has therefore been suggested that ARVs might be delivered via the vertically implemented tuberculosis model, in which a health care worker directly observes treatment-taking behavior. This approach needs to be evaluated in how well it can be applied to HIV treatment programs, as there are a number of significant differences between HIV treatment and TB treatment. For instance, TB treatment consists of a fixed combination of drugs, and this combination does not need to be adapted to suit individual patients. Even more important, TB treatment is taken for a limited period of time, typically for six months in short-course treatment regimens, while antiretroviral treatment is lifelong. The latter requires a different relationship between health care providers and clients and over a much longer period of time. There is certainly merit in some form of observed treatment, but, given that a very large number of people might eventually be on antiretroviral treatment, there is also a need to explore involving non-health provider observers, such as family members, treatment buddies, ${ }^{I}$ or members of the community, as long as they are chosen or identified with the explicit consent of clients and not by the health system alone.

\section{Public and private models}

Many people living with HIV/AIDS will seek care through the private sector, which in many developing countries is still the only source of antiretroviral therapy. This suggests the need for public-private partnerships to build on the strengths of each sector and also to address a number of

\footnotetext{
"Buddy" is a term used to describe a family member, friend, or acquaintance who provides one-on-one support to a person living with HIV/AIDS.
} 
concerns. One concern is the quality and consistency of care. Additional training of both public and private physicians in antiretroviral treatment is needed. Another issue is the very real possibility that clients on treatment will move from provider to provider according to their ability to pay and the availability of drugs. This carries the risk of changes in treatment regimen and thus of drug resistance. In addition, patients with limited financial resources may put pressure on providers to avoid expensive antiretroviral combinations and expensive laboratory tests. This underscores the importance of collaboration, and, when indicated, referral, between the public and private sector.

Within the public sector, questions arise about which type of health care worker should provide antiretroviral therapy, and at what level of the health care system this treatment should be provided. In other words, what is the lowest level at which treatment decisions can be made while still maintaining an acceptable level of quality of care, and what is the lowest level for monitoring treatment?

\section{Antiretroviral treatment programs: Access and equity}

The health care delivery system, whether private or public, plays a key role in providing antiretroviral therapy. Many research questions about these systems were identified at the meeting, some of which are more biomedical but many of which are amenable to an operations research approach. While there is agreement that antiretroviral treatment is only one component of a comprehensive care program, it is not clear what the key components of such a program are and what the appropriate mix of treatment and care is at different levels of the system.

Managers of antiretroviral treatment programs need to make decisions about the number and types of antiretroviral drugs that need to be available, and they need to establish guidelines and treatment protocols. A sustainable and continuous supply of drugs needs to be guaranteed, but the program needs to be flexible enough to adapt to new developments.

Decisions also need to be made about the eligibility of individuals to receive treatment - in other words, what are the criteria a person needs to meet to begin receiving antiretroviral therapy? This in turn raises the issue of equity in access to treatment, or who will have access to ARVs. One of the criteria currently used in Uganda, for instance, is the client's ability to cover the cost of the drugs. While such an approach contributes to the sustainability of the program, it also raises a number of concerns. Current treatment costs, even if subsidized, make treatment unaffordable to many, and may result in the serious risk of treatment interruptions for those who can afford treatment only intermittently. This, obviously, is not a problem in countries where ARVs are made available free of charge through the public sector, although these subsidies come at considerable cost to the government. In Thailand, for instance, 70 percent of the government AIDS budget is allocated to treatment and care, which includes laboratory support, screening, capacity building, treatment for OIs, and ARVs. Even in countries where treatment is free of charge, clients sometimes incur considerable direct and indirect costs, such as transportation and loss of income.

Antiretroviral treatment programs could benefit greatly from involving people living with HIV/AIDS, to assist in planning for service delivery as caregivers and as educators to reduce 


\section{Hgrizons}

stigma and discrimination, and to educate the public, clients, and health care workers. Different approaches to involving PLHA need to be explored and evaluated.

\section{Biomedical Issues}

Antiretroviral therapy is a rapidly evolving field, with new drugs and new drug combinations becoming available continually. While storage requirements have become simpler and treatment regimens have become less complex, further simplification of treatment regimens might make large-scale treatment programs easier to implement and more feasible. Further research and development are also needed to reduce the side effects and toxicity of ARVs. The effects of structured treatment interruptions on quality of life and on viral suppression are currently being explored. Structured treatment interruption might provide a cost-effective approach to maximizing availability of and access to antiretroviral treatment, while minimizing the impact of drug toxicity and side effects on individual patients. Cost savings associated with treatment interruptions might, however, be offset by the need for frequent viral load and CD4 counts to monitor patients.

Resistance to antiretroviral drugs develops rapidly in patients on mono-therapy and more slowly in patients on dual or triple therapy. However, even patients on triple therapy develop resistance, and mechanisms need to be put in place to monitor the response of patients to treatment. Viral strains that are resistant to one or more classes of antiretroviral drugs are especially likely to develop rapidly when adherence to treatment regimens is poor. The presence of resistant strains in a country requires that a larger selection of ARVs be provided, which in turn complicates individual patient management, increases the risk of adverse drug interactions, and increases the demands on the health care and drug logistics systems.

\section{Behavioral Issues}

The health care needs of people living with HIV/AIDS can be seen as a continuum, both in terms of the ever-changing needs as people infected with HIV progress toward AIDS and, in many cases, death, and in terms of the relationships between individuals and their direct environment and the wider community. Figure 3 illustrates the continuum of care as it relates to HIV infection. A comprehensive HIV/AIDS care program must address the full continuum, which usually requires involving a large number of different partners, including PLHA, their families, and health care providers. 
Figure 3 HIVIAIDS and the care and support continuum

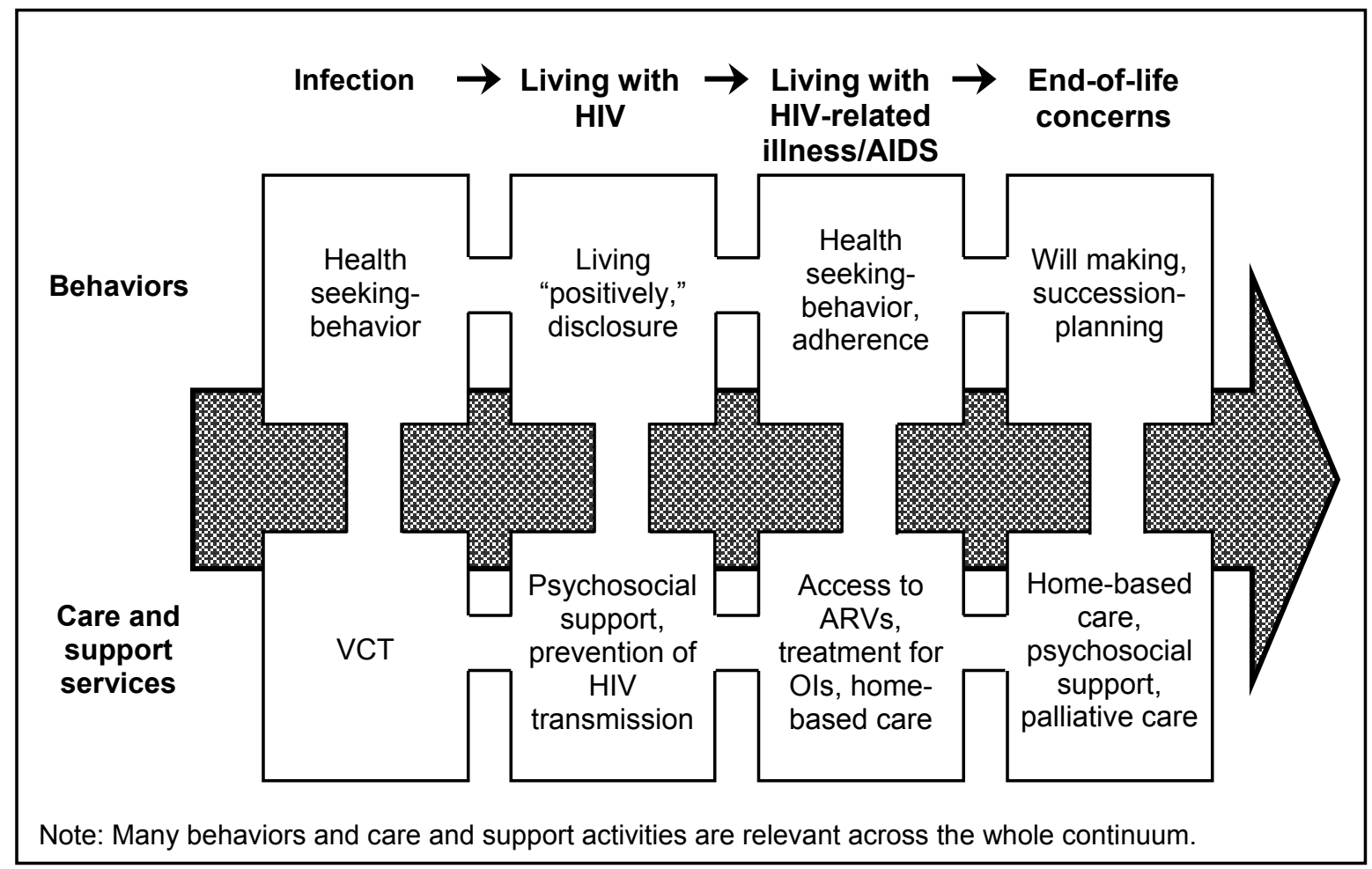

Health-seeking behavior is a complex issue that is influenced not only by the availability of services or treatment, but also by the perceived benefit of such services and by their accessibility and affordability. For example, experience in the United States has shown that migrant workers are often not aware of what services are available to them, have little confidence in public sector services, or may lack the means to access such services. Women in many developing countries have very limited access to available services. Service providers need to understand their clients and their needs and tailor services accordingly. Community-based organizations can play an important role in providing information and education and in working with service providers to increase the coverage and use of services. Community education efforts might help create a more supportive and conducive environment for care and treatment programs, and might lead to more realistic expectations for such programs. Involving people living with HIV/AIDS in care programs can also greatly contribute to a better understanding of the needs of PLHA and might reduce stigma and discrimination within the community, thus reducing an important barrier to care.

A first step in the continuum of care for HIV/AIDS is voluntary counseling and testing, as depicted in Figure 4. VCT services in many countries in the developing world are currently not able to meet the demand for such services. Yet as ARVs become available, it is likely that demand for VCT will increase rapidly. Alternative ways to offer VCT, including making them available outside the 


\section{Hgrizons}

traditional health care system, should be considered and evaluated. Moreover, the impact of testing and counseling on the psychosocial health of individuals needs to be explored.

\section{Figure 4 VCT: An important entry point for HIV prevention and care}

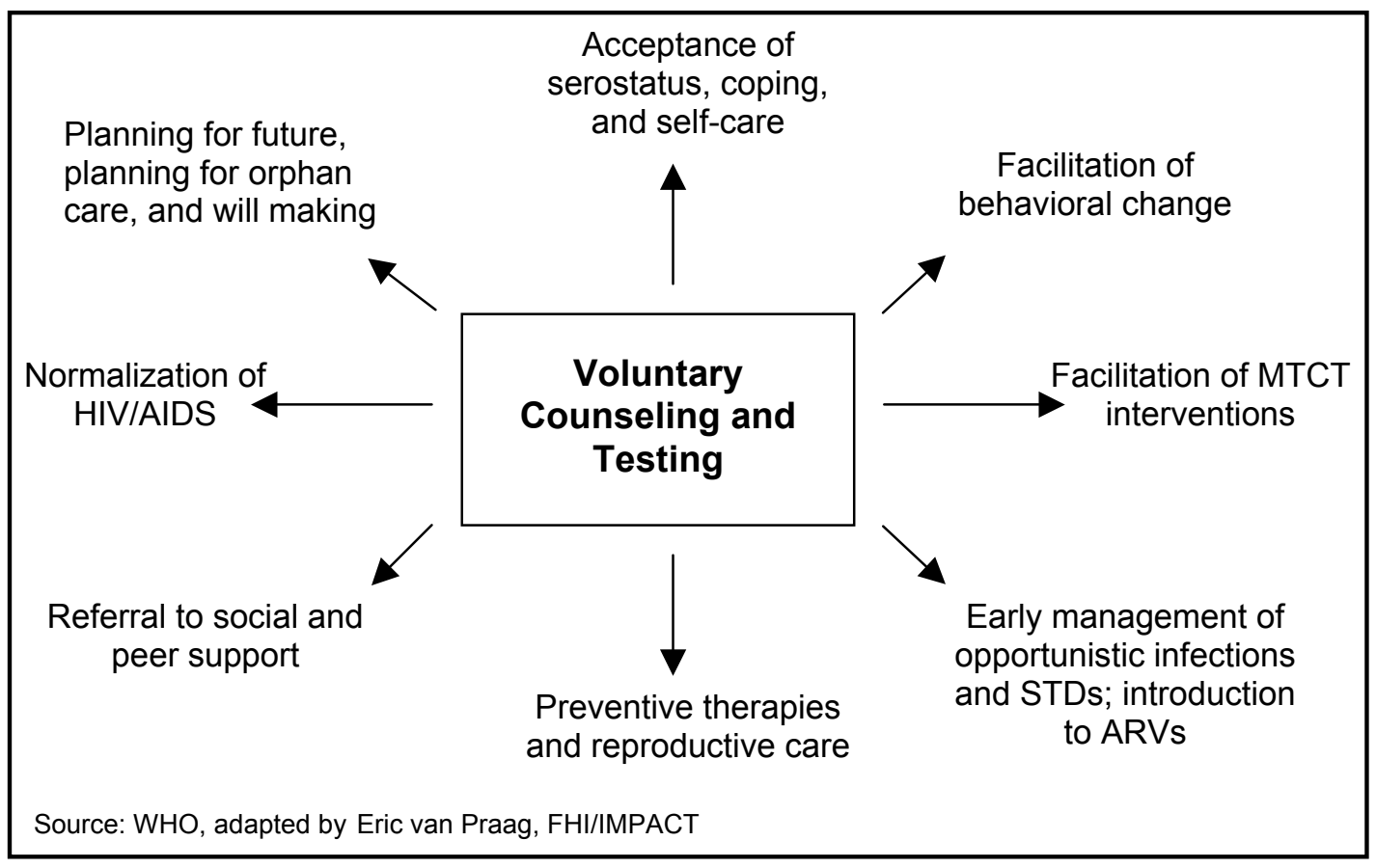

The care continuum for HIV/AIDS, as shown in Figure 4, is characterized by frequent interactions between clients and health care providers, and provider behavior and attitudes are important in determining the acceptability, use, and success of treatment programs. It is important that program managers in treatment programs develop a good understanding of staff attitudes and behaviors and of staff motivation and fears. Staff training and support activities need to address a lack of understanding of the nature of HIV infection and AIDS, fear of contagion, and judgmental and pejorative staff attitudes. In addition, given the strong emotional issues around HIV/AIDS, psychosocial support services for health care staff should be made available. Finally, the care continuum requires good collaboration and referrals between all of the various service providers, institutions, and programs involved.

People with HIV who seek care early on are unlikely to be eligible for or to need antiretroviral therapy. They will often, however, require psychosocial care and support to deal with the knowledge of being infected with HIV and with issues of disclosure, further prevention of infection, and possible stigma and discrimination. Professional sources of psychosocial support are likely to be limited and it is suggested that lay sources be explored. An important source of psychosocial support could be the family and the community, provided that issues of disclosure, 
associated stigma and discrimination, and possible disclosure-related violence are addressed. Psychosocial support is also an important component of home-based, palliative, and end-of-life care.

The provision of antiretroviral therapy raises a large number of behavioral issues, many of which are poorly understood and therefore in need of further research. Clients and communities need to understand that not everyone who is HIV-positive needs immediate treatment; but that once treatment is initiated it needs to be continued lifelong. Moreover, arbitrary treatment interruptions may lead to viral resistance, which may jeopardize future treatment. However, structured treatment interruptions may contribute to long-term adherence, by temporarily removing the pressure of daily treatment adherence and by alleviating side effects of ARVs. Thus, adherence to treatment regimens is a major concern. In Brazil, for instance, intensive public and private sector efforts are made to promote adherence, but these have not been evaluated well enough. It was noted, however, that adherence tends to be poorer for people of lower socioeconomic status.

Little is known about what determines good adherence, and this should be an urgent focus of operations research. Lessons could be learned from directly observed treatment (DOT) programs for tuberculosis, for which treatment defaulting has been linked to an inadequate understanding by patients of the disease and the treatment program. The effect on treatment adherence of an approach that combines early testing and the preparation by the health care provider and the client of a long-term management plan should be explored. Different approaches to ensuring treatment adherence should be evaluated, such as ways to help clients disclose and involve others in adherence, the use of treatment buddies, group approaches to treatment, use of treatment managers (professional or lay), and home and community support.

An area of special concern is the effect of antiretroviral therapy on protective and preventive behaviors. It has been speculated that the availability of antiretroviral therapy has changed the perception of HIV/AIDS from a universally fatal condition to a manageable chronic disease. Consequently, there might be less incentive to adopt and maintain preventive behaviors (Scheer et al. 2001; Stolte 2001 et al.). However, this association has been made on the basis of crosssectional studies that may not necessarily capture other factors that contribute to changes in risk behavior. Longitudinal studies are needed to further explore this issue. It was pointed out by meeting participants that there might be substantial misunderstanding and incorrect interpretation of statements about the outcome of antiretroviral treatment. For instance, statements about an undetectable or low viral load as a consequence of antiretroviral treatment should not be interpreted as meaning that people on treatment are cured or that they cannot infect others. Clarifying these kinds of issues requires a clear communication strategy, not only for patients but also for communities at large.

\section{Stigma, Discrimination, and Ethical Issues}

Successful HIV/AIDS programs, whether they focus on prevention or on care and support, demand careful attention to human rights issues, especially the rights of people living with HIV/AIDS. Some of these rights include the right to know one's HIV status, the right to disclose one's HIV 


\section{Hgrizons}

status, the right to confidentiality, the right to refuse participation in clinical trials, and the right to be treated with dignity and respect. These rights are severely compromised by stigma and discrimination, which still prevail in many parts of the world. For example, fear of stigma and discrimination will likely limit the number of people seeking VCT and thus treatment in some situations, while in others actual discrimination by health care providers reduces access to care and treatment for people living with HIV/AIDS. The impact of involving PLHA in prevention, care, and treatment programs on human rights issues needs to be further evaluated.

The availability of ARVs may lead to a decrease in stigma and discrimination, as seems to have happened in parts of the industrialized world, or it may increase stigma and discrimination. Community involvement, the involvement of PLHA, and a good general understanding by the population of the potential benefits and the limitations of HIV/AIDS treatment and care might help reduce stigma and discrimination. On the other hand, limited availability of treatment in combination with increased disclosure by those seeking treatment or those on treatment might have the opposite effect.

Instruments have been developed in some places to measure stigma and discrimination, but more work needs to be done in this area. Using such indicators would allow for an assessment of the degree to which human rights are respected in service delivery programs and the effect of such programs on stigma and discrimination.

Countries must ensure that the conditions necessary for the health of individuals and populations are met. This responsibility raises questions about equity of access to information, means of prevention, and treatment. At the same time, resources are limited and public health programs are often forced to ration and prioritize. While universal access to cost-effective drugs for palliative care, treatment of opportunistic infections, antiretroviral drugs, and behavior change programs is the ultimate goal, choices have to be made in the meantime that will almost always lead to inequities in access. Broad-based advocacy for access to treatment, as happened in Brazil and Thailand, may increase the demand for and the availability of treatment. In other parts of the world, community mobilization could also prove to be an important step in increasing access to treatment.

It is important that programs define indicators to identify inequities in access to treatment and to monitor progress toward greater equity. In the meantime, many questions remain about who has or will have access to treatment and what criteria should be applied to determine eligibility for ARV treatment. The application of clinical criteria seems fairly uncontroversial, but criteria regarding ability to pay, membership within a particular community, expectations concerning adherence, or geographic location are all likely to result in considerable inequity. While diagnostic studies might document current practices, operations research is urgently needed to support program managers in making sound, ethical decisions to determine access and selection criteria. Such research should also focus on a possible role of communities in deciding on and developing eligibility criteria.

Choices concerning the range of ARVs available in a country also raise ethical questions. What are the implications of introducing a cheaper, but not necessarily optimal, combination of ARVs? For instance, highly active triple antiretroviral therapy might offer the highest success rates, but the cost might also preclude wider coverage of the program. Dual therapy with somewhat cheaper 
drugs might be less effective, but could be offered to a much larger proportion of the eligible population.

A number of ethical issues also arise concerning research, especially concerning clinical trials. Local ethical standards should be applied, but one unanswered question relates to the obligation of researchers after the end of a clinical intervention trial. Should the researchers provide lifelong antiretroviral treatment to study participants? Is there an obligation to extend such treatment to others such as partners of people enrolled in the clinical trial or even to all eligible persons in the community?

\section{Community Involvement}

The community is an essential element in the life of individuals, providing context, cultural identity, and a network for care and support. Yet, with HIV/AIDS, lack of understanding, fear, and stigma and discrimination often mean that such support is lacking and that people living with HIV/AIDS are isolated. Community involvement is thus an important facet of HIV/AIDS programs, to reduce stigma and discrimination and to increase the potential for community care and support. In addition, involving NGOs and community-based organizations (CBOs) in program planning and implementation will probably help in formulating more appropriate and more sustainable programs.

In terms of a community's understanding of HIV/AIDS, a first step is to provide accurate information. Beliefs that either antiretroviral drugs or traditional treatments are curative need to be dispelled, while helping people understand that a range of care and treatment options other than only antiretroviral drugs is available. Training needs to be provided to NGOs to develop their capacity to deal with the various aspects of treatment programs, and to develop partnerships between organizations or institutions providing care, including antiretroviral treatment, and local NGOs and CBOs. Issues that can be addressed through such partnerships include disclosure, stigma and discrimination, community care and support, and resource mobilization. The community is also an essential partner in terms of articulating its needs with regard to a range of other health issues. Communities without established NGOs or CBOs offer a special challenge for community involvement.

NGOs can play an important role in providing and supporting home-based and palliative care. Much can be done in palliative care that would improve the quality of life at relatively little cost. NGOs can also play an important role in helping individuals make decisions about allocating resources for HIV/AIDS and in planning for the future, including ways to care for orphans.

Many NGOs and CBOs working in HIV/AIDS will attract people living with HIV/AIDS as volunteers or collaborators, although fear of stigma may prevent full disclosure. PLHA have, however, a unique role to play in promoting appropriate care and support, in providing insights into adherence issues, and in identifying their education and information needs. 


\section{Hgrizons}

It is essential that community people and community agencies are an integral part because they are not going to leave and they have the passion. (R. Cameron Wolf, HRSA)

Community outreach is an important component of HIV care programs, to improve community understanding, increase health care-seeking behavior, reduce stigma and discrimination, and provide community- and home-based care and support. However, community outreach programs have not been evaluated, and questions remain about the potential and outcomes of home-based care programs, especially concerning training and psychosocial support needs of family health caregivers. One particular group of individuals that could possibly be more involved in care and support are traditional healers. Their involvement fits well with an identified need to tap into the spiritual and broad cultural beliefs of the community.

\section{Cost and Cost Recovery}

Many see the cost of antiretroviral drugs as the limiting factor in making therapy widely available. For instance, cost was identified as a major impediment in scaling up in the UNAIDS pilot programs in Uganda, Chile, Côte d'Ivoire, and Vietnam. Most patients did not have enough resources to pay for the drugs, and this sometimes led to treatment interruptions. Moreover, as new drugs become available and as countries move from single or dual therapy to triple therapy, the cost is likely to increase even more.

While a discussion of the cost of treatment is thus inextricably linked to the broader issue of access to treatment, many unanswered questions need to be investigated. An important question concerning any intervention is whether it is affordable, replicable in a larger geographic area, cost effective, and sustainable over time. In other words, is the intervention worth the investment of scarce resources?

In terms of affordability and sustainability, one should balance the cost of treatment against the individual and societal savings that might accrue from treatment. It is also necessary to consider who pays for treatment (government, individuals, insurance agencies, NGOs) against who benefits and how many people benefit. For instance, who is willing and able to contribute to treatment costs? While a patient on treatment might use household savings to pay for treatment, being on treatment might also guarantee continued income to the household.

In terms of providers, there is not enough experience with providing antiretroviral therapy to know what the direct and indirect costs are for service providers, and what the health care system will save in terms of future care costs. Little is also known about the short-term and long-term costs and savings to society. The larger the savings to society (the external benefits of treatment of individuals that accrue to the society), the stronger the argument for subsidizing antiretroviral treatment. Related to this issue is the question of the potential for community mobilization of resources. Different approaches to funding and resource mobilization, including insurance plans and risk pooling, need to be explored and evaluated. 
As was pointed out earlier, there is a moral imperative to provide the best possible treatment to people who are ill with HIV/AIDS. The scarcity of resources, however, means that treatment programs will be in competition with other programs and that even within treatment programs, choices will have to be made. Some of these choices are discussed under the Health System and Service Delivery section. Cost-effectiveness analyses could assist in making such choices, but many questions still remain about measuring cost-effectiveness of HIV/AIDS treatment programs. One such question is, what is the objective of the program? For instance, measuring outcomes in terms of reduced mortality or of disability-adjusted life years ${ }^{2}$ gained focuses on direct individual benefits but does not capture external outcomes. Measuring effectiveness requires a clear, unambiguous definition of outcomes at multiple levels: individual, family, community, and society.

Given the resource constraints under which many countries are operating, a case could also be made to evaluate and compare the cost-effectiveness and cost benefits of antiretroviral treatment programs against the cost-effectiveness and cost benefits of other public health programs, such as malaria control, diarrhea control, and family planning.

\section{Policy}

The success of the antiretroviral therapy program in Brazil in providing treatment to substantial numbers of PLHA has been attributed to high levels of political support and the adoption of countrywide policies. A federal law passed in 1996 guarantees that ARVs will be provided for any person who needs them. An important factor in generating this political commitment has been the presence and activities of vocal and well-organized NGOs and political activists. Similarly, the success of the Thailand antiretroviral treatment program can be ascribed to the political will and the commitment to allocate a substantial proportion of the available resources to care and treatment of PLHA. In all fairness, it should be noted that in both Brazil and Thailand the resource base is much larger and the prevalence of HIV/AIDS is much lower than in many other developing countries, especially those in Sub-Saharan Africa. Even so, in Brazil a policy has been adopted to allocate considerable resources to the manufacture and importation of generic versions of patent-protected drugs to meet the country's needs.

But even in resource-constrained settings, governments can do much to create an environment that is conducive to effective prevention as well as appropriate care and support. Legislation against discrimination against those with HIV/AIDS and active promotion of their human rights will facilitate disclosure and help to strengthen services that respect and provide care for PLHA. Legislation and policies are needed to ensure the availability of condoms and other barrier methods, youth-friendly services, interventions to prevent transmission through drug injections to treat opportunistic infections, and, eventually, antiretroviral drugs. Research is needed to better understand and evaluate approaches to generating appropriate policy support for prevention, care, and support.

\footnotetext{
${ }^{2}$ Disability-adjusted life years (DALYs) provide a measure of the burden of disease, taking into account both death and disability (loss of quality of life) caused by a disease (World Development Report 1993).
} 


\section{Hgrizons}

\section{Programmatic Implications}

To implement a successful, sustainable HIV/AIDS care and support program, a number of programmatic decisions need to be made. Further operations research is needed to inform such decisions, but some programs will certainly be implemented in the absence of research results. Among the many programmatic issues that have been identified as important are discussed below.

HIV/AIDS programs need to balance prevention and care, and care programs need to take into account the needs of people living with HIV/AIDS along a continuum. This continuum ranges from testing, counseling, and psychosocial support to treatment of opportunistic infections, prevention of mother-to-child transmission, treatment with ARVs, and, finally, palliative and end-of-life care. The resources available and the epidemiological situation will influence the appropriate mix of activities along this continuum, but even a modest treatment program will require an expansion of VCT programs for HIV-positive individuals so that they are identified.

For an antiretroviral therapy program to be successful, important decisions have to be made concerning the types and combinations of drugs that are made available, the criteria used to select PLHA to receive antiretroviral treatment, and the treatment delivery program that needs to be developed and implemented. Care should be taken to ensure equitable access to treatment, although it is unlikely that true equity will be achieved early on in treatment programs. Innovative approaches to promote treatment adherence need to be tested, such as the joint (client and provider) development of a treatment plan, the use of a treatment manager (health professional or lay person), or the use of a treatment buddy system. Communities and PLHA should be actively involved in the planning as well as implementation stages of the program, and the effect of such involvement should be evaluated.

In addition, program managers need to develop and implement training programs for health care providers in the public and private sector, paying attention not only to clinical skills and knowledge, but also to attitudes and motivation.

One of the biggest challenges, however, of an HIV/AIDS treatment program is to scale up in an equitable and sustainable manner. Lessons can be learned from experiences with the scaling up of programs to prevent MTCT. 


\section{Conclusion}

Providing antiretroviral therapy as a component of comprehensive HIV/AIDS care is rapidly becoming a reality in some countries and is becoming a distinct possibility in many other developing countries. Many questions remain, however, about the most effective, equitable, costeffective, and, above all, balanced implementation of such programs. Biomedical research will yield new and better drugs that are less toxic and easier to take. Clinical research will continue to improve and adapt drug combinations, taking into account viral resistance and side effects. However, considerable operations research is urgently needed to identify, analyze, and disseminate best experiences with treatment programs in different resource and epidemiological situations. A list of high-priority operations research questions is provided below, as formulated by the international experts participating in the Horizons Access to Treatment meeting. Although many of these research questions can be addressed in the context of ongoing or newly established treatment programs, there are advantages to identifying specific learning sites for ARV programs in which different models of VCT and treatment provision can be tested and evaluated.

\section{High-priority Operations Research Questions}

\section{Health systems}

1. What is the most appropriate mix of care interventions in settings with considerable resource constraints? What is the most effective way to identify the different needs of different groups (for example, by age, sex, or geographical location) for care?

2. What are the factors and characteristics that make for successful service delivery programs? What are the benefits of models with centralized versus decentralized providers?

3. What is needed to improve the motivation and confidence of health care workers? Specifically, what is needed in terms of training, salaries, support, and backstopping? What training is needed for health care workers in the private sector?

4. Where and at what level of the health care system can antiretroviral therapy be provided? What are the minimum requirements for infrastructure, laboratory support, combination of drugs, staff, and community involvement that are needed to maintain a basic standard of quality of care?

5. What are the quality of care and the use of different service delivery models? How can quality of service be ensured?

6. How can the potential of private providers best be maximized? What are models for successful public-private sector partnerships? 


\section{Hgrizons}

\section{Behavioral questions including adherence}

1. Which factors contribute to adherence to treatment, for both OIs and ARV therapy?

2. What is the impact of comprehensive care and prevention programs on adherence?

3. How does the use of non-medical providers affect maintenance of treatment regimens? What is the effect on adherence of using a buddy system compared to treatment managers or to involvement of family and/or community?

4. Can ARVs be introduced without reducing protective behaviors? Will the introduction of ARVs increase high-risk behaviors?

\section{Equity and accessibility}

1. How equitable is the provision of treatment (for both OIs and ARVs) and what are the criteria being used to select recipients of ART? How are these criteria developed, applied, and enforced?

2. What are the specific needs of different groups in a society for care and treatment, and who can best meet these needs?

3. From an epidemiological and a public health benefits standpoint, are there some high-risk groups that should receive priority in receiving treatment?

\section{Community involvement}

1. What processes or approaches help ensure the meaningful involvement of communities in designing and implementing HIV/AIDS care and treatment programs? What is the effect of involving communities in designing and implementing treatment and care programs? What is the role of communities in care provision?

2. What are the community's preferences for accessing treatment, in terms of sources of care and types of care?

3. What is the effect of involving PLHA on the coverage, use, and success of treatment programs?

4. What is the effect of comprehensive programs that treat families rather than individuals? 


\section{Cost}

1. What are the most feasible and effective models for resource mobilization, including risk pooling, insurance, and community resource mobilization?

2. What is the range of costs and cost-effectiveness for different care options, including antiretroviral therapy and treatment for opportunistic infections? What is the range of costs and cost-effectiveness for different treatment options?

3. How much will care and support for people living with HIV/AIDS cost? What is the benchmark for cost-effectiveness? How big are the externalities ${ }^{3}$ associated with care and support, and how can these be maximized?

4. What proportion of therapy can user fees cover? What is the willingness and ability of clients to pay for different treatment options?

5. What is the implication of user fees on the financial wellbeing of families?

\section{Stigma, discrimination, and ethical issues}

1. Which training or other approaches are likely to reduce reducing stigma and discrimination among health care providers?

2. What effect will scaling up VCT and care and support programs have on stigma and discrimination? What is the effect of the availability of treatment on stigma and discrimination?

3. What type of care, support, and treatment interventions will reduce stigma and discrimination in the community and in the health care sector?

4. What is the scope for providing antiretroviral therapy for prevention purposes? What are the ethical and patient management implications of such therapy?

\footnotetext{
${ }^{3}$ Externalities are the benefits that go beyond the individual benefits, such as, for instance, the benefit to society of a person returning to an economically productive life.
} 


\section{Hgrizons}

\section{References}

AIDS Epidemic Update: December 2001. 2001.Geneva: UNAIDS and WHO.

Eyer-Silva, W.A. et al. 1998. "Decline in AIDS-related deaths at a university hospital in Rio de Janeiro, Brazil." International Conference on AIDS 12:120 (abstract no. 13176).

Gray R.H. et al. 2001. "Probability of HIV-1 transmission per coital act in monogamous, heterosexual, HIV-1 discordant couples in Rakai, Uganda.” Lancet 357: 1149-1153.

HIV/AIDS Surveillance Report, Vol. 12, No. 2. 2000. CDC-NCHSTP-DHAP. Atlanta: Centers for Disease Control and Prevention.

Lucas G.M., R.E. Chaisson, and R.D. Moore. 1999. "Highly active antiretroviral therapy in a large urban clinic: Risk factors for virologic failure and adverse drug reactions. Annals of Internal

Medicine 131: 81-87.

Ministry of Health of Brazil: June 2001. National AIDS Drug Policy/Ministry of Health, National STD/AIDS Programme. http://www.aids.gov.br.

Remien R.H. et al. 1998. "Perceptions, attitudes, and sexual risk among HIV-positive men with undetectable plasma viral loads." International Conference on Aids 12:419 (abstract no. 23389).

Scheer S. et al. 2001. "Effect of highly active antiretroviral therapy on diagnoses of sexually transmitted diseases in people with AIDS. Lancet 357(9254):432-435.

Servais J. et al. 2000. "Three-year effectiveness of highly active antiretroviral treatment in the Luxembourg HIV cohort.” HIV Clinical Trials 1(2): 17-24.

Stolte I.G. et al. 2001. "Increase in sexually transmitted infections among homosexual men in Amsterdam in relation to HAART.” Sexually Transmitted Infections 77(3):184-186.

World Bank. World Development Report 1993. 1993. Oxford: Oxford University Press, pp. 25-26.

Yamashita T.E. et al. 2001. "Immunologic and virologic response to highly active antiretroviral therapy in the Multicenter AIDS Cohort Study." AIDS 15:735-746. 


\section{Appendix A}

\section{Recommended Further Reading}

AIDS: Palliative care. October 2000. UNAIDS Technical Update.

http://www.unaids.org/publications/documents/care/general/JC-PalliCare-TU-E.pdf.

Developing HIV/AIDS treatment guidelines. 1999. UNAIDS Best Practice Collection.

http://www.unaids.org/publications/documents/health/reform/developingkme.pdf.

WHO and UNAIDS. 1998. Nine guidance modules on antiretroviral treatments. WHO/ASD/98.1, Geneva. http://www.who.int/HIV_AIDS/antiretroviral_modules/indexar.htm.

WHO, UNAIDS, and International AIDS Society. 2000. Safe and effective use of ARV treatments in adults with particular reference to resource limited settings. WHO/HSI/2000.04, Geneva. http://www.who.int/HIV_AIDS/WHO_HIS_2000.04_1.04/001.htm.

2001 USPHS/IDSA. 2001. Guidelines for the prevention of opportunistic infections in persons infected with HIV. http://www.hivatis.org/trtgdlns.html.

Panel on Clinical Practices for Treatment of HIV Infection convened by the Department of Health and Human Services (DHHS) and the Henry J. Kaiser Family Foundation. 2002. Guidelines for the use of antiretroviral agents in HIV-infected adults and adolescents.

http://www.hivatis.org/trtgdlns.html.

Working Group on Antiretroviral Therapy and Medical Management of HIV-Infected Children convened by the National Resource Center (NPHRC), the Health Resources and Services Administration (HRSA), and the National Institutes of Health. 2001. Guidelines for the use of antiretroviral agents in pediatric HIV-infection. http://www.hivatis.org/trtgdlns.html.

Perinatal HIV Guidelines Working Group. 2002. Public Health Service Task Force recommendations for the use of antiretroviral drugs in pregnant HIV-1 infected women for maternal health and interventions to reduce perinatal HIV-1 transmission in the United States. http://www.hivatis.org/trtgdlns.html.

Centers for Disease Control and Prevention. 2000. "Updated guidelines for the use of rifabutin or rifampin for the treatment and prevention of tuberculosis among HIV-infected patients taking protease inhibitors or nonnucleoside reverse transcriptase inhibitors." Morbidity and Mortality Weekly Report (March 10). www.hivatis.org/trtgdlns.html

Centers for Disease Control and Prevention. 2001. "Updated U.S. Public Health Service guidelines for the management of occupational exposures to HBV, HCV, and HIV and recommendations for post-exposure prophylaxis." Morbidity and Mortality Weekly Report (June 29).

www.hivatis.org/trtgdlns.html. 


\section{Hgrizons}

\section{Appendix B}

\section{List of Participants at Horizons Access to Treatment Meeting 12 and13 June 2001 Washington, D.C.}

Barbara Aranda-Naranjo

Director

HIV/AIDS Bureau-Special Projects of National Significance

Health Resources and Services Administration 5600 Fishers Lane, 7C-07

Rockville, MD 20857

Phone : 301-443-2399

Fax : 301-443-4965

BAranda-Naranjo@hrsa.gov

Simon Baker, Ph.D.

Program Associate

Horizons/Program for Appropriate

Technology in Health

Population Council

P.O. Box 138 Pratunam Post Office

Bangkok, Thailand

Phone: 66-2-251-4766

Fax: 66-2-253-5513

simon@popcouncil.th.com

Mary Bassett, M.D., M.P.H.

Associate Director

Health Equity

Rockefeller Foundation

Southern Africa Regional Office

7th Floor, Kopje Plaza

No.1 Jason Moyo Avenue

Harare, Zimbabwe

Phone: 011-263-4-780-978

Fax: 011-263-4-781-769

mbassett@rockfound.org.zw

Francisco Inácio Bastos, M.D., Ph.D. Associate Researcher

Oswaldo Cruz Foundation

Av. Brasil, 4365 Biblioteca de Manguinhos 209

Rio de Janeiro 21045-900

Brazil

Fax : 55-21-2702668

bastos@fiocruz.br fibastos@gbl.com.br
Lisanne Brown, Ph.D.

Research Assistant Professor

Department of International Health and Development

Tulane School of Public Health and Tropical Medicine

1440 Canal St., Suite 2200

New Orleans, LA 70112

Phone: 504-584-1978

Fax: 504-584-3653

br71365@mailhost.tcs.tulane.edu

Chris Castle

Program Associate

Horizons/International HIV/AIDS Alliance

Population Council

4301 Connecticut Ave. N.W., Suite 280

Washington, DC 20008

Phone: 202-237-9400

Fax: 202-237-8410

ccastle@pcdc.org

John Casterline, Ph.D.

Senior Associate

Policy Research Division

Population Council

One Dag Hammerskjold Plaza

New York, NY 10017

Phone: 212-339-0500

Fax:: 212-755-6052

jcasterline@popcouncil.org

Henry E. Chang

Executive Director

Global Immunity

AIDS Healthcare Foundation

40 W. 22nd Street, Suite 9B

New York, NY 10010

Phone/Fax: 212-242-1782

hechang@aol.com 
Dr Anupong Chitwarakorn

Director

Department of Communicable Disease Control Ministry of Health

88/21 Moo 4 Tivanont Rd.

Ampher Muang,

Nonthaburi 11000 Thailand

Phone: 5918411-2

Fax: 5918413

anupongc@health.moph.go.th

Celine Costello Daly, M.D.

Program Associate

Horizons

Population Council

53 Lodi Estate, $3^{\text {rd }}$ Floor

New Delhi 110003 India

Phone: 91-11-464-290/2

Fax: 91-11-461-0912

cdaly@pcindia.org

Margaret Dadian

Program Associate

Communications, Dissemination, and Utilization Unit

Horizons

Population Council

4301 Connecticut Ave N.W., Suite 280

Washington, DC 20008

Phone: 202-237-9400

Fax: 202-237-8410

mdadian@popcouncil.org

Gray Davis, Ph.D.

Consultant

START Project

Family Health International

P.O. Box 13950

Research Triangle Park, NC 27709

Phone: 919-544-6979

Fax: 919-544-7261

gdavis@fhi.org

Judith Diers

Special Assistant to the President

Office of the President

Population Council

One Dag Hammerskjold Plaza

New York, NY 10017

Phone: 212-339-0500

Fax: 212-755-6052

jdiers@popcouncil.org
William Duncan, Ph.D.

Associate Director for Therapeutics Research Programs Division of AIDS

National Institute of Allergy and Infectious Diseases

National Institutes of Health

6700B Rockledge Dr., Room 5101

Bethesda, MD 20892-7624

Phone: 301-496-8210

Fax: 301-480-4582

wd6u@nih.gov

Iyeme Efem

AIDS Program Coordinator

PLAN International

1730 N. Lynn St.

Arlington, VA 22209

Phone: 703-807-1264. Ext. 103

Fax: 703-807-1274

efemi@childreach.org

Terry Elliott, M.Sc.

Senior Program Officer

Program for Appropriate Technology

in Health

4 Nickerson Street

Seattle, WA 98102

Phone: 206-285-3500

Fax: 206-285-6619

telliott@path.org

Eka Esu-Williams, Ph.D.

Program Associate

Horizons

Population Council

Box 411744

Craighall 2024

Johannesburg

South Africa

Phone: 27-11-325-0518

Fax: 27-11-325-0647

ewilliams@pcjoburg.org.za

Andy Fisher, Sc.D.

Director and Senior Associate

Horizons

Population Council

4301 Connecticut Ave N.W., Suite 280

Washington, DC 20008

Phone: 202-237-9400

Fax: 202-237-8410

afisher@pcdc.org 


\section{Hgrizons}

\author{
A.K. Ganesh, B.Com. A.C.A. \\ Project Manager \\ YRG Care \\ 1, Ramen St \\ T Nagar, Chennai 600017 \\ India \\ Phone: 91-44-826-4242/8240311 \\ Fax: 91-44-825-6900 \\ yrgcare@vsnl.com \\ Laelia Gilborn \\ Program Associate \\ Horizons \\ Population Council \\ 4301 Connecticut Ave. N.W., Suite 280 \\ Washington, DC 20008 \\ Phone: 202-237-9400 \\ Fax: 202-237-8410 \\ lgilborn@pcdc.org
}

Rod Hoff

Senior Epidemiologist for International Research

Division of AIDS Research

National Institute of Allergy and Infectious Diseases

National Institutes of Health

31 Center Drive MSC 2520

Bethesda, MD 20892-2520

Phone: 301-496-6179

Fax: 301-402-3684

rhoff@niaid.nih.gov

Rick Homan, Ph.D.

Senior Research Associate

Health Services Research

Family Health International

P.O, Box 13950

Research Triangle Park, NC 27709

Phone: 919-544-6979, ext. 309

Fax: 919-544-7261

rhoman@fhi.org

Sam Kalibala, M.D.

Program Associate

Horizons

Population Council

General Accident Insurance House

Ralph Bunche Rd

P.O. Box 17643

Nairobi, Kenya

Phone: 254-2-713-480

Fax: 254-2-713-479

skalibala@popcouncil.or.ke

skalibala@hotmail.com
Deanna Kerrigan, Ph.D.

Program Associate

Horizons/Johns Hopkins University

Population Council

4301 Connecticut Ave, N.W., Suite 280

Washington, DC 20008

Phone: 202-237-9400

Fax: 202-237-8410

dkerrigan@pcdc.org

Stephen Kinoti, MBChB, MMED, MPSID

HIV/AIDS Advisor

SARA Project

Academy for Educational Development

1875 Connecticut Ave. N.W.

Universal North 9th Floor, Suite 909A

Washington, DC 20009

Phone: 2028848236

Fax: 202-84-8447

skinoti@aed.org

Elke Konings, M.Sc., Ph.D.

Senior Program Associate

Management Sciences for Health

165 Allandale Road

Boston, MA 02130

Phone: 617-524-7799, ext. 241

ekonings@msh.org

Eve Lackritz

Chief

Care and Support

Global AIDS Program

National Center for HIV, STD, and TB Prevention

Centers for Disease Control and Prevention 1600

Clifton Rd.

Mailstop E-41

Atlanta, GA 30333

Phone: 404-639-6105

Fax: 404-639-4268

eal3@cdc.gov

Mark Lurie, Ph.D., Senior Scientist

Africa Centre for Population Studies and Reproductive Health

South African Medical Research Council

P.O. Box 17120

Congella 4013 Durban

South Africa

Phone: 27-31-277-4000

Fax: 27-31-202-0950

luriem@mrc.ac.za 
Ron MacInnis

Health Advisor

Africa Bureau

U.S. Agency for International Development

1325 G St., N.W., Suite 400

Washington, DC 20005

Phone: 202-219-0473

Fax: 202-216-3373

rmacinnis@afr-sd.org

Ann McCauley, Ph.D.

Program Associate

Horizons/International Center for

Research on Women

Population Council

4301 Connecticut Ave., N.W., Suite 280

Washington, DC 20008

Phone: 202-237-9400

Fax: 202-237-8410

amccauley@pcdc.org

Jeanne McDermott, C.N.M., M.P.H., Ph.D.

Program Officer

Division of International Training and Research

Fogarty International Center

National Institutes of Health

Building 31, Room B2C39

31 Center Drive MSC2220

Bethesda, MD 20892-2220

Phone: 301-496-1492

Fax: 301-402-0779

mcdermoj@mail.nih.gov

Naisiadet Mason

International Program Coordinator

National Association of People Living with AIDS-USA

1413 K Street, N.W., 7th Floor

Washington, DC 20005

Phone: 202-898-0414, ext.102

Fax: 202-898-0435

nmason@napwa.org

Paolo Miotti, M.D.

Office of AIDS Research

National Institutes of Health

2 Center Drive

Bethesda, MD 20892

Phone: 301-402-2474

pm122m@nih.gov
Peter Mugyenyi, F.R.C.P., Director

Joint Clinical Research Center

P.O. Box 10005

Kampala

Uganda

Phone: 256-41-270-622

Fax: 256-41-342-632

pmugyenyi@yahoo.co.uk

Dr. Ya Diul Mukadi

Sr. Technical Ofiicer

Technical Support/Care Group

Family Health International

2101 Wilson Boulevard, Suite 700

Arlington, VA 22201

Phone: 703-516-9779

Fax: 703-516-9781

ydmukadi@fhi.org

Dr. Paula Munderi

Medical Officer

HIV Care Team

World Health Organization

Attn: Dr. A. Kochi

Coordinator, Dept. of HIV/AIDS

Director, Care and Support, HIV/AIDS

20 Avenue Appia

CH-1211 Geneva 27

Switzerland

Phone 41-22-791-21-11

Fax: 41-22-791-31-11

munderip@who.ch

Lewis Ndhlovu, Ph.D.

Program Associate

Horizons

Population Council

Box 411744

Craighall 2024

Johannesburg

South Africa

Phone: 27-11-325-0518

Fax: 27-11-325-0647

lndhlovu@pcjoburg.org.za 


\section{Hgrizons}

\author{
Dr. Jos Perriens \\ Manager \\ Strategy Development for Responses \\ Strategic Information \\ Social Mobilization and Information Department \\ UNAIDS \\ 20 Avenue Appia \\ CH-1211 Geneva 27 \\ Switzerland \\ Phone: 4122 7914456/4569 \\ Fax: 41227914741 \\ perriensj@who.int \\ Dr. Carla Pettinelli \\ Chief Treatment Research Branch \\ Division of AIDS Research \\ National Institute of Allergy and Infectious Diseases \\ National Institutes of Health \\ Building 6700B, Room 5102 \\ 31 Center Drive MSC 2520 \\ Bethesda, MD 20892-2520 \\ Phone: 301-496-0700 \\ cp22n@nih.gov \\ Julie Pulerwitz, Sc.D. \\ Program Associate \\ Horizons/ Program for Appropriate Technology in \\ Health \\ Population Council \\ 4301 Connecticut Ave. N.W., Suite 280 \\ Washington, DC 20008 \\ Phone: 202-237-9400 \\ Fax: 202-237-8410 \\ jpulerwitz@pcdc.org \\ Geeta Rao Gupta \\ President \\ International Center for Research on Women \\ 1717 Massachusetts Ave., N.W. \\ Suite 302 \\ Washington, DC 20005 \\ Phone: 202-797-0007 \\ Fax: 202-797-0020 \\ geeta@icrw.org \\ Dr. Somsong Rugpao Director General \\ Department of Communicable Disease Control \\ Ministry of Public Health \\ 88/21 Moo 4 Tivanont Rd. \\ Ampher Muang, \\ Nonthaburi 11000 Thailand \\ rugpoa@health.moph.go.th
}

Naomi Rutenberg, Ph.D.

Research Director

Horizons

Population Council

4301 Connecticut Ave. N.W., Suite 280

Washington, DC 20008

Phone: 202-237-9400

Fax: 202-237-8410

nrutenberg@pcdc.org

David Stanton

Technical Advisor

Acquired Immune Deficiency Syndrome Division

Center for Population, Health, and Nutrition

U.S. Agency for International Development

G/PHN/HN/HIV-AIDS

$3^{\text {rd }}$ floor RRB-USAID

Washington, DC 20523-3700

Phone: 202-712-5681

Fax: 202-216-3046

dstanton@usaid.gov

Mike Sweat, Ph.D.

Assistant Professor of International Health

Department of International Health

School of Hygiene and Public Health

Johns Hopkins University

615 North Wolfe St.

Room E7140

Balitmore, MD. 21205

Phone: 410-614-4536

Fax: 703-995-0615

msweat@jhsph.edu

Johannes van Dam, M.D., M.P.H.

Deputy Director

Horizons

Population Council

4301 Connecticut Ave., N.W., Suite 280

Washington, DC 20008

Phone: 202-237-9400

Fax: 202-237-8410

jvandam@pcdc.org

Janneke van de Wijgert, Ph.D.

Program Associate

Reproductive Health

Population Council

One Dag Hammerskjold Plaza

New York, NY 10017

Phone: 212-339-0500

Fax: 212-755-6052

jvandewijgert@popcouncil.org 
Eric van Praag, M.D., M.P.H.

Director

HIV Care and Support

HIV/AIDS Prevention and Care Department

Family Health International

2101 Wilson Boulevard, Suite 700

Arlington, VA 22201

Phone: 7035169779

Fax: 7035169781

evanpraag@fhi.org

Sten Vermund, Ph.D.

Department of Geographic Medicine

University of Alabama at Birmingham

$84519^{\text {th }}$ St. South

Room 206

Department of Geographic Medicine

Birmingham, AL 35294-2170

Phone: 205-975-7613

Fax: 205-933-5671

sten@geomed.dom.uab.edu

Helena Walkowiak, B.Pharm. M.Sc.

Senior Program Associate

Center for Pharmaceutical Management

Management Sciences for Health

4301 North Fairfax Drive, Suite 400

Arlington, VA 22203-1627

Phone: 703-248-1636

Fax: 703-524-7898

hwalkowiak@msh.org
Ellen Weiss

Research Utilization Director

Horizons/International Center for

Research on Women

Communications, Dissemination, and Utilization Unit Population Council

4301 Connecticut Ave. N.W.

Suite 280

Washington, DC 20008

Phone 202-237-9400

Fax: 202-237-8410

eweiss@pcdc.org

David Wilson

Project Support Group

University of Zimbabwe

4 Lorna Rd.

Mt. Pleasant

Harare, Zimbabwe

Phone: 263-4-304921

Fax: 263-4-333-407

dwilson@esanet.zw

R. Cameron Wolf, Ph.D., Sc.M.

International Monitoring and Evaluation Consultant

HIV/AIDS Bureau-Office of Science and

Epidemiology

Health Resources and Services Administration

5600 Fishers Lane, 7C-07

Rockville, MD 20857

Phone : 301-443-2399

Fax : 301-443-4965

cwolf@hrsa.gov 


\title{
Hgrizons
}

\section{Appendix C}

\author{
Access to Treatment for HIVIAIDS: \\ Directions for Operations Research Consultative Meeting \\ 12 and 13 June 2001
Washington Plaza Hotel, Jefferson Room
Massachusetts Ave. and $14^{\text {th }}$ Street N.W.
Washington, D.C.

\section{Objectives}

Assist the Horizons Program in refining and prioritizing operations research questions that address access to treatment for HIVIAIDS, and to identify potential research partners. The meeting will focus on the following key questions:

1. What are the operational issues encountered in providing HIVIAIDS treatment in different country settings?

2. What are the most important operational challenges and testable solutions in providing access to treatment?

3. How do these challenges and solutions differ by region and subpopulation?

4. What are some of the important research design and measurement issues that need to be considered in addressing key access to treatment issues?

\section{Agenda}

Tuesday, June 12

\begin{tabular}{|c|c|}
\hline $9: 00-10: 00$ & $\begin{array}{l}\text { Introduction of participants and objectives } \\
\text { Andrew Fisher, Horizons }\end{array}$ \\
\hline $10: 00-10: 40$ & $\begin{array}{l}\text { Overview And Discussion of Access to Treatment Services } \\
\text { Eric van Praag, FHI/IMPACT }\end{array}$ \\
\hline $10: 40-11: 00$ & Coffee Break \\
\hline $11: 00-11: 30$ & $\begin{array}{l}\text { USAID's Access to Treatment Priorities and Programs } \\
\text { David Stanton, USAID }\end{array}$ \\
\hline $11: 30-12: 00$ & $\begin{array}{l}\text { Reaching the Hard to Reach in the United States: Treatment Priorities and } \\
\text { Program Approaches } \\
\text { Barbara Aranda-Naranjo and R. Cameron Wolf, HRSA }\end{array}$ \\
\hline $12: 00-12: 30$ & $\begin{array}{l}\text { Discussion } \\
\text { Moderator: Simon Baker, Horizons }\end{array}$ \\
\hline $12: 30-1: 30$ & Lunch \\
\hline
\end{tabular}




\begin{tabular}{|c|c|}
\hline Balance of Day & $\begin{array}{l}\text { Critical reflection on country experiences with access to tre } \\
\text { for HIVIAIDS: What does a country need to do to increase acce } \\
\text { treatment? What are the challenges? What are the potential sol } \\
\text { What operations research has been done within countries on ac } \\
\text { issues? What was learned? What research needs to be done? } \\
\text { is } 15 \text { minutes for each presentation followed by } 5 \text { minutes for cla } \\
\text { questions. After all of the country presentations, a general discu } \\
\text { follow. }\end{array}$ \\
\hline $1: 30-1: 50$ & $\begin{array}{l}\text { UNAIDS Four Country Pilot Provision of ARVs } \\
\text { Jos Perriens, UNAIDS }\end{array}$ \\
\hline 1:50 - 2:10 & $\begin{array}{l}\text { Thailand } \\
\text { Somsong Rugpao and Anupung Chitwarakorn, Department of } \\
\text { Communicable Disease Control, Ministry of Health, Thailand }\end{array}$ \\
\hline $2: 10-2: 30$ & $\begin{array}{l}\text { Uganda } \\
\text { Peter Mugyenyi, Joint Clinical Research Centre }\end{array}$ \\
\hline $2: 30-3: 00$ & $\begin{array}{l}\text { Discussion } \\
\text { Moderator: Ann McCauley, Horizons }\end{array}$ \\
\hline $3: 00-3: 20$ & Break \\
\hline $3: 20$ - 3:40 & $\begin{array}{l}\text { Brazil } \\
\text { Francisco Inácio Bastos, Oswaldo Cruz Foundation }\end{array}$ \\
\hline $3: 40-4: 00$ & $\begin{array}{l}\text { South Africa } \\
\text { Mark Lurie, Medical Research Council, South Africa }\end{array}$ \\
\hline $4: 00-4: 20$ & $\begin{array}{l}\text { India } \\
\text { A.K. Ganesh, YRG Care }\end{array}$ \\
\hline $4: 20-5: 00$ & $\begin{array}{l}\text { Discussion } \\
\text { Moderator: Naomi Rutenberg, Horizons }\end{array}$ \\
\hline $5: 00-6: 30$ & Reception \\
\hline
\end{tabular}

Wednesday, June 13

9:00 - 9:30 Synopsis of Challenges and Solutions from Previous Day Johannes van Dam, Horizons

Balance of Day Discussion of Five Key Topics: For each topic, identify operations research questions, design and measurement challenges, problem areas, and potential testable solutions. 


\section{Hgrizons}

9:30 - 10:20 Service Delivery, Illustrative Questions: What are the supplies, equipment, and logistics issues that need to be addressed? What are the provider competence issues? How can we create PLHA-friendly treatment centers? What are the implications for voluntary testing and counseling of increased access to treatment? Is there an opportunity to change MTCT programs, moving from single therapy to triple therapy?

Presenter: Sam Kalibala, Horizons

Moderator: Helena Walkowiak, MSH

10:20 - 10:40 Coffee Break

$10: 40-11: 30$

Behavioral Issues, Illustrative Questions: How can a high level of patient adherence to drug regimens be maintained? Is a DOT program feasible? Are there dangers of an increase in unsafe sex practices as ARV patients perceive themselves to not be at risk?

Presenter: Julie Pulerwitz, Horizons

Moderator: Mary Bassett, University of Zimbabwe

11:30 - 12:20 Community Involvement, Illustrative Issues: What is the role of communities and NGOs in access to treatment? How can they foster a high level of patient adherence and facilitate information dissemination, particularly among low-literate populations?

Presenter: Eka Esu-Williams, Horizons

Moderator: Stephen Kinoti, SARA Project, AED

$12: 20-1: 30$

Lunch

1:30 - 2:20 Human Rights, Illustrative Questions: What are the human rights, equity, ethical, and gender issues concerning who will have access to treatment? Can treatment programs reduce stigma and discrimination? How can treatment programs accurately track patients without stigmatizing them?

Presenter: Chris Castle, Horizons

Moderator: Ron Maclnnis, USAID

2:20 - 3:00 Cost, Illustrative Questions: What are the operational cost issues that need to be examined? Is fee for services a viable approach?

Presenter: Rick Homan, FHI

Moderator: Mike Sweat, Johns Hopkins University

3:00-3:20 Break

3:20 - 4:10 Setting Operations Research Priorities for Horizons

Moderator: Johannes van Dam, Horizons

4:10 - 4:20 Wrap-up

Andrew Fisher, Horizons 


\section{Hqrizons}

Horizons is a global operations research program designed to:

- Identify and test potential strategies to improve HIV/AIDS prevention, care, and support programs and service delivery.

- Disseminate best practices and utilize findings with a view toward scaling up successful interventions.

For more information, please contact:

Horizons Program, Communications Unit 4301 Connecticut Avenue, NW Suite 280 Washington, DC 20008 USA

Tel: 202-237-9400

Fax: 202-237-8410

Email: horizons@pcdc.org

www.popcouncil.org/horizons/horizons.html

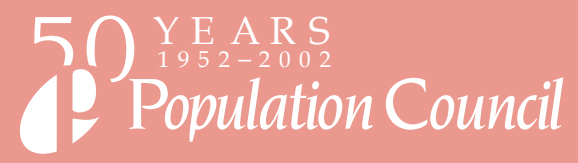

Horizons is implemented by the Population Council in collaboration with

- International Center for Research on Women (ICRW)

- International HIV/AIDS Alliance

- Program for Appropriate Technology in Health (PATH)

- Tulane University

. University of Alabama at Birmingham

- Family Health International (FHI)

- Johns Hopkins University 